\title{
Correlation between Fitness and Fatness in 6-14-year Old Serbian School Children
}

\author{
Sergej M. Ostojic ${ }^{1,2}$, Marko D. Stojanovic', Vladan Stojanovic ${ }^{2}$, \\ Jelena Maric ${ }^{2}$, and Nenad Njaradi' \\ 'Biomedical Sciences Department, Faculty of Sport and Tourism, Novi Sad, Metropolitan University, Belgrade, Serbia, and \\ ${ }^{2}$ Exercise Physiology Laboratory, City Center for Physical Culture, Belgrade, Serbia
}

\begin{abstract}
Lack of physical activity and/or physical fitness are some reasons epidemiologists suggest for increase in childhood obesity in the last 20 years, with clear correlation between body composition and physical activity and/or physical fitness yet to be determined. The objectives of the study were to (a) investigate the prevalence of overweight and obesity among Serbian school children and (b) determine the relationship between indicators of physical activity and body fatness in Serbian school children aged 6-14 years. The study subjects included a representative sample of Serbian elementary school children ( $n=1,121-754$ boys and 367 girls-aged 6.2-14.1 years), all of whom were recruited in the OLIMP (Obesity and Physical Activity among Serbian School Children) study. Anthropometric and physical fitness values, including body mass index (BMI), waist-circumference, body-fat, and aerobic capacity, were measured in all the children. Significant differences were found between male and female children regarding the prevalence of obesity (6.8\% vs $8.2 \%$, $\mathrm{p}<0.05$, boys and girls respectively). Boys had significantly lower body mass, BMI, waist-circumference, sum of six skinfolds, and body-fat compared to their female counterparts $(\mathrm{p}<0.05)$. The highest level of weight, BMI, body-fat, and waist-circumference observed in a 14-year old girl $\left(96.3 \mathrm{~kg}, 40.5 \mathrm{~kg} / \mathrm{m}^{2}\right.$, $54.5 \%, 91.4 \mathrm{~cm}$ respectively) implies the existence of extreme obesity in Serbian school children. The negative relationship between body-fat and maximal oxygen $\left(\mathrm{VO}_{2} \max \right)$ uptake was moderately high $(\mathrm{r}=-0.76$; $\mathrm{p}<0.05)$. The study has shown a high prevalence of adiposity among Serbian school children, with a strong negative relationship between aerobic fitness and body fatness. Data of the study emphasize the necessity to identify children with weight problems and to develop early interventions to improve physical activity in children and prevent the increase of childhood obesity.
\end{abstract}

Key words: Body-fat; Cross-sectional studies; Fitness; Girls; Obesity; Serbia

\section{INTRODUCTION}

The prevalence of childhood obesity has been increasing dramatically worldwide, particularly in the last two decades (1-3). Although the prevalence of overweight and obesity varies quite substantially across ethnic groups and gender, numerous studies have shown alarmingly high levels of being fat among children. Estimates in

Correspondence and reprint requests should be addressed to:

Prof. Sergej M. Ostojic

Biomedical Sciences Department

Exercise Physiology Laboratory

Faculty of Sport and Tourism

Metropolitan University

Radnicka 30/II, Novi Sad 21000

Serbia

Email: sergej@panet.rs

Fax: (++381)-21-530-232 several studies indicate that one in four children aged 6-14 years is presently overweight in developed and developing countries $(4,5)$, which ranges from $11 \%$ to $39 \%$ (6-9). The prevalence of overweight and obesity was found similar (9) or significantly different (10) between genders, with difference found in studies that reported higher prevalence of overweight and obesity in either girls (11-13) or boys (14). It is unclear what cultural, lifestyle, genetic, or environmental factors may explain these differences (15). The level of prevalence varies substantially with geographical region in European school children and is reported to be as high as $27.7 \%$ and $28 \%$ for boys and girls of the Eastern region respectively (16). To the best of our knowledge, to date, no published data are available regarding the prevalence rates of overweight and obesity for Serbian school children. 
Lack of physical activity and/or physical fitness and excessive calorie consumption are some reasons epidemiologists suggest for the increase of obesity in the last 20 years $(4,17)$. The low level of physical activity and health-related physical fitness, represented by cardiorespiratory (aerobic) endurance, seems to contribute to the development of obesity, type 2 diabetes, hypercholesterolaemia, hypertension, the metabolic syndrome, cardiovascular diseases, and all-cause mortality in both adults and children (18-20). Since the habitual levels of physical activity are closely related to cardiorespiratory fitness, submaximal and maximal exercise testing has become frequently-used indirect physical activity-assessment methods. Results of several studies showed that overweight subjects performed more poorly on cardiorespiratory fitness tests than their thinner counterparts, with low to moderately-high inverse correlations found between cardiorespiratory fitness and adiposity $(10,21,22)$.

Although it would appear plausible to assume that the higher level of physical fitness in children results in a more favourable body-composition, data that permit examination of relationship between aerobic fitness and body-fatness in youths are limited and considered controversial $(23,24)$. Moreover, little is known about the relationship between physical fitness and different body-fatness indicators besides body mass index (BMI), such as waist-circumference or percentage of body-fat, in children. To the best of our knowledge, no data are available examining interdependence between obesity and physical activity indicators in Serbian school children. Therefore, the study was carried out to (a) investigate the prevalence of overweight and obesity among Serbian school children and (b) determine the relationship between physical activity and body-fatness indicators in Serbian school children aged 6-14 years.

\section{MATERIALS AND METHODS}

\section{Study subjects}

The evaluation was performed during September 2007-May 2008 among 1,121 healthy school children of the elementary school programme. Stratified (geographically) random sampling was used in this cross-sectional study. Ten schools were identified from the Department of Education and were randomly selected from the Belgrade borough area of Zvezdara on a proportional basis. Principals of the schools were contacted with the aims of the study explained to both physical education teachers and school administrators. Once a school had agreed to participate in the study, letters to parents were distributed. They completed a sports participation and medical history questionnaire and were informed that they could withdraw from the study at any time, even after giving their written consent. Children with conditions that might have led to limitations in physical activity and mobility were excluded. All the participants were in good health, free from musculoskeletal dysfunctions, and metabolic and heart diseases. None of the subjects was on the medication at the time of the study.

\section{Experiment design}

Each child underwent a one-day testing session. During this session, anthropometric assessment and physical fitness test were carried out. Height was measured using a stadiometer (Seca 202, USA) to the nearest $0.1 \mathrm{~cm}$ while body mass was obtained to the nearest $0.1 \mathrm{~kg}$ using a calibrated balance beam scale (Avery Ltd, Model 3306 ABV, UK). The subjects were measured with underwear only, in the same state of hydration and nourishment after voiding. All anthropometric measurements were taken between 9 and 11 am after an overnight fasting between 10 and 12 hours. BMI was calculated as weight $(\mathrm{kg}) /$ height $(\mathrm{m})^{2}$. Children were considered overweight or obese based on age-specific BMI reference guidelines (Table 1) $(25,26)$. Waist-circumference was measured using a Gulick anthropometric tape (Creative Health Products, Plymouth, USA) at the level of the narrowest point between the lower costal border and the iliac crest. Skinfold thickness at six sites was obtained using a Harpenden caliper (British Indicators Ltd., St. Albans, UK). The skinfold sites were biceps, triceps, subscapular, suprailiac, abdominal, and medium calf. The landmarks were identified and measured according to Wilmore and Behnke, with the median of three measurements used for representing skinfold thickness

\begin{tabular}{|c|c|}
\hline Status category & Percentile range \\
\hline Underweight & Less than the 5 th percentile \\
\hline Normal weight & 5th to less than the 85 th percentile \\
\hline Overweight & 85th to less than the 95 th percentile \\
\hline Obese & Equal to or greater than the 95 th percentile \\
\hline
\end{tabular}


(27). The percentage of body-fat was determined according to age- and gender-specific equations (girls, percentage of body-fat $=0.610$.(triceps skinfold $[\mathrm{mm}]+$ calf skinfold $[\mathrm{mm}])+5.1$; boys, percentage of body-fat $=0.735$. (triceps skinfold $[\mathrm{mm}]+$ calf skinfold $[\mathrm{mm}])+1.0)(28)$. The same trained technician performed tests on each subject for anthropometric measurements according to the International Society for the Advancement of Kinathropometry. Aerobic fitness was determined using maximal multistage 20-m shuttle-run test (29). Subjects were required to run back and forth on a 20-m course and be on the 20-m line at the same time a beep is emitted from a tape. The frequency of sound-signals increased in such a way that running speed starts at $8.5 \mathrm{~km} / \mathrm{h}$ and was increased by $0.5 \mathrm{~km} / \mathrm{h}$ each minute. When the subjects could no longer follow the pace, the stage the subjects were able to run for was recorded and used for calculating the maximal oxygen $\left(\mathrm{VO}_{2} \max \right)$ uptake. This test has shown to be valid and reliable for the prediction of the $\mathrm{VO}_{2} \max$ in children (30).

\section{Statistical analysis}

Descriptive statistics were run on all the variables. Statistical significance between continuous variables was assessed using unpaired Student's $t$-test, with $\mathrm{p}$ values of less than 0.05 considered statistically significant. Categorical data were evaluated using chisquare $\left(\chi^{2}\right)$ analysis. The relationship between bodyfat, BMI, and waist-circumference and $\mathrm{VO}_{2}$ max was examined using Pearson's product-moment correlation coefficient. Data were analyzed using the SPSS, PC program (version 14.0) (SPSS Inc., USA).

\section{Ethics}

All the participants and parents were fully informed verbally and in writing about the nature and demands of the study. All the subjects and parents gave their informed consent and volunteered to participate in the study with the approval of the University's Ethical Advisory Commission in accordance with the Helsinki Declaration.

\section{RESULTS}

The prevalence of overweight was $32 \%$ and did not vary among the girls and boys $(32.2 \%$ and $31.5 \%$ respectively) (Fig. 1). Significant differences were observed between male and female children regarding the prevalence of obesity (6.8\% vs $8.2 \%$, $\mathrm{p}<0.05$, boys and girls respectively). The mean values for anthropometric and physiological data are shown in Table 2. Both boys and girls had com-

Fig. 1. Percentage of overweight and obese subjects



$\square$ Normal $\square$ Overweight $\square$ Obese

Total $(\mathrm{n}=1,121)$

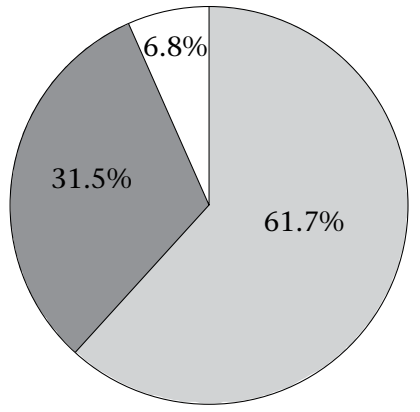

$\square$ Normal $\square$ Overweight $\square$ Obese

Boys $(n=754)$

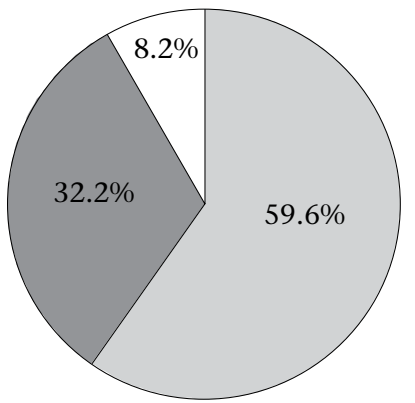

$\square$ Normal $\square$ Overweight $\square$ Obese Girls $(n=367)$

Table 2. Characteristics (mean $\pm \mathrm{SD}$ ) of the study subjects by gender

\begin{tabular}{|lcccc|}
\hline Variable & Boys $(\mathrm{n}=754)$ & Girls $(\mathrm{n}=367)$ & Range & Total $(\mathrm{n}=1,121)$ \\
\hline Age $($ years $)$ & $10.4 \pm 3.1$ & $10.8 \pm 2.8$ & $6.2-14.2$ & $10.5 \pm 3.0$ \\
Height $(\mathrm{cm})$ & $141.6 \pm 12.5$ & $142.4 \pm 13.7$ & $122.5-188.2$ & $141.9 \pm 12.9$ \\
Body mass $(\mathrm{kg})$ & $37.1 \pm 10.8$ & $38.3 \pm 11.5^{*}$ & $20.1-96.3$ & $37.5 \pm 11.0$ \\
BMI $(\mathrm{kg} / \mathrm{m} 2)$ & $18.5 \pm 2.4$ & $18.9 \pm 2.5^{*}$ & $14.3-40.5$ & $18.6 \pm 2.4$ \\
Waist-circumference $(\mathrm{cm})$ & $62.5 \pm 8.4$ & $66.1 \pm 11.4^{*}$ & $44.5-91.4$ & $64.9 \pm 10.4$ \\
Sum of 6 skinfolds $(\mathrm{mm})$ & $63.2 \pm 15.3$ & $74.1 \pm 22.6^{*}$ & $18-114$ & $66.8 \pm 17.7$ \\
Body-fat $(\%)$ & $20.3 \pm 9.1$ & $24.9 \pm 9.7^{*}$ & $3.0-54.5$ & $21.8 \pm 9.3$ \\
VO ${ }_{2}$ max $(\mathrm{mL} / \mathrm{kg} / \mathrm{min})$ & $34.1 \pm 12.4$ & $30.4 \pm 9.6^{*}$ & $10.3-63.2$ & $32.9 \pm 11.5$ \\
\hline${ }^{*} \mathrm{p}<0.05$ boys vs girls; BMI:Body mass index; SD=Standard deviation; $\mathrm{VO}_{2}$ max=Maximal oxygen uptake \\
\hline
\end{tabular}


parable age and height. Boys showed significantly lower body-mass, BMI, waist-circumference, sum of six skinfolds, and body-fat compared to their female counterparts $(\mathrm{p}<0.05)$. Moreover, boys attained better performance in multistage fitness test and had, therefore, higher $\mathrm{VO}_{2} \max (\mathrm{p}<0.05)$. The highest level of weight, BMI, body-fat, and waistcircumference observed in a 14-year old girl (96.3 $\mathrm{kg}, 40.5 \mathrm{~kg} / \mathrm{m}^{2}, 54.5 \%$, and $91.4 \mathrm{~cm}$ respectively) implies the existence of extreme obesity in Serbian school children. The relationship between bodyfat and $\mathrm{VO}_{2} \max$ is illustrated in Figure 2. The correlation coefficient was moderately high ( $\mathrm{r}=-0.76$;
The prevalence of obesity (6.8-8.2\%) among the study children did not differ from other national studies in a similar age-group. The prevalence of obesity in children and youths was 8.2\% in Aboriginal and non-Aboriginal Canadians (31). Vissers et al. reported 7.5\% prevalence of obesity in Belgian adolescents, with different prevalence of overweight and obesity among subjects with different types of education (32). The prevalence of obesity among children from Spain was 5-8\% (10) while it was $7.9 \%$ among boys and $4.7 \%$ among girls in Qatari adolescents (33).



$\mathrm{p}<0.05)$. There was significant inverse correlation between waist-circumference and $\mathrm{VO}_{2} \max (\mathrm{r}=-$ 0.43 ; $\mathrm{p}<0.05)$, with insignificant correlation between $\mathrm{BMI}$ and $\mathrm{VO}_{2} \max (\mathrm{r}=-0.09 ; \mathrm{p}>0.05)$.

\section{DISCUSSION}

The data of the present study clearly demonstrated that a strong negative correlation existed between aerobic fitness and body-fat in Serbian school children aged 6-14 years. The data also demonstrated a high prevalence of both overweight and obese children (39\%); the prevalence of overweight was similar among boys and girls. Moreover, girls had inferior cardiorespiratory fitness compared to their male counterparts.
Childhood obesity is becoming a global epidemic and is threatening to have reached epidemic proportions in Serbia. When children who were obese and overweight by BMI criteria were considered together, more alarming data generated as higher values of overweight and obese children found (39\%) were superior compared to other national studies. About 33\% of Baltimore school children were overweight and obese based on the age-specific BMI reference values (34). The prevalence of overweight, including obesity, was higher among boys (25.7\%) than among girls (19.1\%) in the representative sample of Spanish adolescents $(n=2,859)(35)$. Al-Nakeeb et al. indicated that over $37 \%$ of boys and girls from Birmingham fell into overweight and obese 
classifications, with one (22\%) in five children having more than 30\% body-fat (12). Furthermore, the obese group was almost girl-exclusive (90\%). The authors reported that $71 \%$ of children had a percentage of body-fat in excess of $20 \%$, which is recognized as the upper end of the optimal range for this age-group. Like previous research, data in the present study indicate that the prevalence of overweight is similar among boys and girls. Girls tend to have a higher prevalence of obesity than boys (8.2\% vs $6.8 \%$ respectively). Other indices of adiposity, including skinfolds, waist-circumference, and percentage of body-fat, provided rates of prevalence of overweight and obesity similar to those obtained with age-specific BMI classification. The sex difference in the prevalence of obesity may be related to maturation, growth history, and behavioural and environmental factors, which limits our interpretation and requires more investigation. An interesting gender difference was suggested considering sexual maturation, with early sexual maturation positively associated with overweight and obesity in girls but the associations were reverse for boys (36). In addition, the primary behavioural and environmental factors are food-consumption patterns, sedentary behaviour, socioeconomic status, and micro- (family) and macro- (local society) environment (4). The gradual increase in body-weight that leads to obesity is the consequence of a prolonged positive energy balance, i.e. when energy intake exceeds energy loss. There are many factors that can influence energy balance and, therefore, be identified as contributors to the current obesity epidemic in children, with biological, behavioural, environmental, and social being most cited (37). Although relative contribution of energy intake versus energy loss to the obesity epidemic is a source of continuing debate, available data clearly indicate that physical activity plays an integral role in the prevention of obesity $(17,18,23)$. Obese children are at an increased risk of acute medical illnesses and chronic diseases, particularly osteoarthritis, diabetes mellitus, and cardiovascular diseases, which can lead to the poor quality of life, an increased personal and financial burden to individuals, families, and society, and a shortened lifespan (38).

The average $\mathrm{VO}_{2} \max$ for children assessed in the present study $(32,9 \mathrm{~mL} / \mathrm{kg} / \mathrm{min})$ was lower than previously reported. Studies using procedures for direct measurement of $\mathrm{VO}_{2} \max$ have recorded values between 34 and $58 \mathrm{~mL} / \mathrm{kg} / \mathrm{min}$ for children aged 8-12 years (39-41), with boys having a higher value of $\mathrm{VO}_{2} \max$ than girls. Using the testing protocol similar to the present study, Leger and co- workers reported aerobic capacity from 38 to 52 $\mathrm{mL} / \mathrm{kg} / \mathrm{min}$ for children aged 6-18 years (42). Such discrepancy is likely to be the result of differences in body-composition and level of physical activity, which induce well-established secular trend of decline in aerobic capacity among children (43). The gender differences in $\mathrm{VO}_{2}$ max found in our study (34.1 \pm 12.4 vs $30.4 \pm 9.6$ for boys and girls respectively) is in accordance with previous studies. Aerobic capacity is consistently greater in boys throughout childhood, with the gender gap widening at the puberty (44). The observed difference has been ascribed to a combination of factors, including bodycomposition and cardiac size and function (45).

Regular physical activity plays an important role in the maintenance of body-weight and composition and in the regulation of skeletal muscle and adipose tissue metabolism. Several investigators reported an association between physical activity and body-composition in children $(5,10,12,35,37,46)$. Precise assessment of habitual physical activity is critical for accurate descriptive epidemiology of the physical activity-obesity relationship for designing appropriate interventions aimed at modifying body-composition and related risk factors and for promoting change in lifestyles (38). However, since physical activity is complex, multidimensional behaviour and precise measurement remain a challenge for practitioners, researchers, and healthcare providers, especially among children.

Self-reported physical activity questionnaire and physiological measures of fitness (direct and indirect assessments of $\mathrm{VO}_{2} \mathrm{max}$ ), with several objective techniques, such as heart rate monitors, pedometers, and accelerometers, have been used extensively for the measurement of physical activity in children (47). Although objective techniques are a superior tool for the assessment of physical activity, they are often impractical and time-consuming, thus implying that indirect assessment of physical activity could be more appropriate in studies with a large sample. Moreover, study of aerobic fitness and body-fat is probably a more valid approach than measurement of self-reported physical activity and body-weight, particularly in children $(48,49)$.

It has been reported that overweight and obese children showed a lower physical fitness (cardiorespiratory endurance) than normal children $(50,51)$. However, studies analyzing an association between cardiorespiratory fitness and different measures of body-composition in this population are scarce. Our results showed a strong inverse relationship $(\mathrm{r}=-0.76)$ between aerobic fitness and percentage of 
body-fat in both boys and girls. The results in terms of other anthropometrical variables showed both significant (with waist-circumference) and insignificant (with BMI) relationship with cardiorespiratory fitness, which has also been reported earlier in children and adolescents $(46,48)$. Klasson-Heggebo et al. found a curvilinear-graded relationship between cardiorespiratory fitness and waist-circumference and sum of skinfolds in 4,072 children and adolescents aged 9 and 15 years respectively, from Denmark, Portugal, Estonia, and Norway, with abundant data showing a significant inverse relationship between physical activity level and bodyfat percentage (50). Hence, it is not surprising that people who have sedentary lifestyles also have low levels of fitness and excessive body-fat (48). Given that this study was cross-sectional in design, causeand-effect conclusions are not warranted. However, it appears that the goal of favourably altering adiposity in children should begin with increasing physical activity and fitness, which, in turn, will lead to reductions in body-fat. Moreover, children who improve their cardiorespiratory fitness during childhood have less overall adiposity and less abdominal adiposity than their counterparts during adolescence and adulthood (3). Participation in vigorous physical activities has been shown to relate inversely to fat deposition in both children and adults $(5,18,38,52)$. Due to the fact that BMI poorly correlates with aerobic fitness, other indicators of adiposity (body-fat, waist-circumference) rather than weight has been shown to be associated with cardiorespiratory fitness $(19,37)$. Several investigators provided evidence that a combination of simple measures, such as triceps and calf skinfolds, waist-circumference, and perhaps fitness, should be used in clinical settings to identify children with high risk of obesity $(49,51,53)$.

Our results suggest that cardiorespiratory fitness as an indicator of physical activity is linked to the increased level of adiposity in children. Inactivity is only one of the factors interconnected with obesity; however, it is perhaps one of the easiest to modify (37). Considering that physical education is the only source of regular physical activity for many children (54), improvement in physical education class may be prudent. The main aim of such classes should be to engage children in healthproviding physical activity levels in contrast to the present curriculum design for movement skills development. Moreover, it has been proved that physical education can have an important role in promoting participation of children in extra-curricular health-enhancing physical activity $(55,56)$. Guidelines for physical activity in youths recommend involvement in moderate to vigorous physi- cal activities for at least 60 minutes a day for health promotion and from a weight-control perspective (18). According to the results of the present study and the fact that Serbian academic curriculum includes only 90-minute physical activity per week, initiatives should be put forward to promote physical activity in Serbian children in both school and out-of-school environment.

\section{Limitations}

A clear understanding of the relationship between physical activity and/or physical fitness and bodycomposition in children in the present study may not be possible due to several limitations. Despite the value of endurance test for indirect measurement of physical activity in children, it has been stated that more accurate measures of physical activity are required to determine if an association truly exists between activity level of children and their aerobic fitness on obesity (52). Moreover, the analysis of fitness-fatness association will be further improved with adjustment for pubertal development factors, which requires further investigation. The need for parental agreement and consent might have also lead to bias, with those parents more committed to physical activity agreeing to participation of their children (51). Finally, it can be said that BMI is a relatively weak substitute for measuring the percentage of body-fat and, thereby, obesity (37). Combination of BMI with body-fat and physical fitness needs to be used for establishing a more relevant standard definition for childhood overweight and obesity worldwide (53).

\section{Conclusions}

The results of the present study showed that bodyfat and waist-circumference negatively correlated with aerobic fitness, suggesting that children who have high cardiorespiratory fitness during childhood have less overall adiposity and less abdominal adiposity than their unfit counterparts. Furthermore, the prevalence of overweight and obesity in Serbian school children was high, with girls having higher obesity rates than boys. Although there are many factors that can contribute to obesity among children, this study emphasizes the necessity to develop interventions to improve physical fitness in children and to prevent the increase of childhood obesity.

\section{ACKNOWLEDGEMENTS}

The Serbian Ministry of Science supported the study (Grant No. 145082). The authors declare no conflict of interest. 


\section{REFERENCES}

1. Ogden CL, Flegal KM, Carroll MD, Johnson CL. Prevalence and trends in overweight among US children and adolescents, 1999-2000. JAMA 2002;288:1728-32.

2. Hedley AA, Ogden CL, Johnson CL, Carroll MD, Curtin LR, Flegal KM. Prevalence of overweight and obesity among US children, adolescents, and adults, 1999-2002. JAMA 2004;291:2847-50.

3. Tjepkema M. Adult obesity. Health Rep 2006;17:9-25.

4. Lobstein T, Baur L, Uauy R. Obesity in children and young people: a crisis in public health. Obes Rev 2004;5:S4-85.

5. Brunnet M, Chaput, J-P, Tremblay A. The association between low physical fitness and high body mass index or waist circumference is increasing with age in children: the 'Quebec en Forme' Project. Int J Obes 2007;31:637-43.

6. Kotani K, Nishida M, Yamashita S, Funahashi T, Fujioka S, Tokunaga $\mathrm{K}$ et al. Two decades of annual medical examinations in Japanese obese children: do obese children grow into obese adults? Int J Obes 1997;21:912-21.

7. Wang Y, Monteiro C, Popkin BM. Trends of obesity and underweight in older children and adolescents in the United States, Brazil, China, and Russia. Am J Clin Nutr 2002;75:971-7.

8. Manios Y, Moschandreas J, Hatzis C, Kafatos A. Health and nutrition education in primary schools of Crete: changes in chronic disease risk factors following a 6-year intervention programme. Br J Nutr 2002;88:315-24.

9. Kain J, Uauy R, Vio F, Albala C. Trends in overweight and obesity prevalence in Chilean children: comparison of three definitions. Eur J Clin Nutr 2002;56:200-4.

10. Ara I, Moreno LA, Leiva MT, Gutin B, Casajús A . Adiposity, physical activity, and physical fitness among children from Aragon, Spain. Obesity 2007;15:1918-24.

11. National Center for Health Statistics. Overweight among US children and adolescents. NHANES Data Briefs 2002;1-2.

12. Al-Nakeeb Y, Duncan MJ, Lyons M, Woodfield L. Body fatness and physical activity levels of young children. Ann Hum Biol 2007;34:1-12.

13. Tremblay MS, Katzmarzyk PT, Willms JD. Temporal trends in overweight and obesity in Canada, 19811996. Int J Obes 2002;26:538-43.

14. Krassas GE, Tzotzas T, Tsametis C, Konstantinidis T. Prevalence and trends in overweight and obesity among children and adolescents in Thessaloniki, Greece. J Pediatr Endocrinol Metab 2001;14:S1319-26.

15. Cole TJ, Bellizzi MC, Flegal KM, Dietz WH. Establishing a standard definition for child overweight and obesity worldwide: international survey. BMJ 2000;320:1240-3.

16. Jackson-Leach R, Lobstein T. Estimated burden of paediatric obesity and co-morbidities in Europe. Part 1. The increase in the prevalence of child obesity in Europe is itself increasing. Int J Ped Obes 2006;1:26-32

17. Roberts SB, Lucas A, Hirsch J. Low energy expenditure as a contributor to infant obesity. Am J Clin Nutr 2000;71:154-6.

18. Molnar D, Livingstone B. Physical activity in relation to overweight and obesity in children and adolescents. Eur J Pediatr 2000;159:S45-5.

19. Ross R, Kartzmarzyk PT. Cardiovascular fitness is associated with diminshed total and abdominal obesity independent of body mass index. Int J Obes Realt Metab Disord 2003;27:204-10.

20. Wong SL, Katzmarzyk P, Nichaman MZ, Church TS, Blair SN, Ross R. Cardiorespiratory fitness is associated with lower abdominal fat independent of body mass index. Med Sci Sports Exerc 2004;36:286-91.

21. Winsley JR, Armstrong N, Midlebrooke RA, RamosIbanez N, Williams CA. Aerobic fitness and visceral adipose tissue in children. Acta Poediat 2006;95:1435-8.

22. Lee SJ, Arslanian SA. Cardiorespiratory fitness and abdominal adiposity in Youth. Eur J Clin Nutr 2007; 61:561-5

23. Goran MI, Reynolds KD, Lindquist $\mathrm{CH}$. Role of physical activity in the prevention of obesity in children. Int J Obes Relat Metab Disord 1999;23:S18-33.

24. Molnar D, Livingstone B. Physical activity in relation to overweight and obesity in children and adolescents. Eur J Pediatr 2000;159:S45-5.

25. Kiess W, Galler A, Reich A, Müller G, Kapellen T, Deutscher J et al. Clinical aspects of obesity in childhood and adolescence. Obes Rev 2001;2:29-36.

26. Flodmark CE, Lissau I, Moreno LA, Pietrobelli A, Widhalm K. New insights into the field of children and adolescents' obesity: the European perspective. Int J Obes Relat Metab Disord 2004;28:1189-96.

27. Wilmore JH, Behnke AR. An anthropometric estimation of body density and lean body weight in young men. J Appl Physiol 1969;27:25-31.

28. Slaughter MH, Lohman TG, Boileau RA, Horswill CA, Stillman RJ, Van Loan MD et al. Skinfold equations for estimation of body fatness in children and youth. Hum Biol 1988;60:709-23.

29. Leger LA, Lambert J. A maximal multistage 20-m shuttle run test to predict $\mathrm{VO}_{2}$ max. Eur J Appl Physiol 1982;49:1-12.

30. van Mechelen W, Hlobil H, Kemper HC. Validation of two running tests as estimates of maximal aero- 
bic power in children. Eur J Appl Physiol Occup Physiol 1986;55:503-6.

31. Katzmarzyk PT. Obesity and physical activity among Aboriginal Canadians. Obesity 2008;16:184-90.

32. Vissers D, Devoogdt N, Gebruers N, Mertens I. Truijen, Van Gaal L. Overweight in adolescents: differences per type of education. Does one size fit all? J Nutr Educ Behav 2008;40:65-71.

33. Bener A. Prevalence of obesity, overweight, and underweight in Qatari adolescents. Food Nutr Bull 2006;27:39-45.

34. Jehn ML, Gittelsohn J, Treuth MS, Caballero B. Prevalence of overweight among Baltimore city schoolchildren and its associations with nutrition and physical activity. Obesity 2006;14:989-93.

35. Ortega FB, Tresaco B, Ruiz JR, Moreno LA, Martin-Matillas M, Mesa JL et al. Cardiorespiratory fitness and sedentary activities are associated with adiposity in adolescents. Obesity 2007;15:1589-99.

36. Wang Y. Is obesity associated with early sexual maturation? A comparison of the association in American boys versus girls. Pediatrics 2002;110:902-9.

37. Rowlands AV, Eston RG, Ingledew DK. Relationship between activity level, aerobic fitness, and body fat in 8to 10-yr-old children. J Appl Physiol 1999;86:1428-35.

38. Dugan SA. Exercise for preventing childhood obesity. Phys Med Rehabil Clin N Am 2008;19:205-16.

39. Cooper DM, Weiler-Ravell D, Whipp BJ, Wasserman $\mathrm{K}$. Aerobic parameters of exercise as a function of body size during growth in children. J Appl Physiol 1984;561:628-34.

40. Washington RL, von Gundy JC, Cohen C, Sondheimer HM, Wolfe RR. Normal aerobic and anaerobic exercise data for North American school-age children. J Pediatr 1988;112:223-33.

41. Duncan GE, Mahon AD, Howe CA, Corral PD. Plateau in oxygen uptake at maximal exercise in male children. Pediatr Exerc Sci 1996;8:77-86.

42. Leger LA, Mercier D, Gadoury C, Lambert J. The multistage 20-meter shuttle run test for aerobic fitness. $J$ Sports Sci 1988;6:93-101.

43. Tomkinson GR, Léger LA, Olds TS, Cazorla G. Secular trends in the performance of children and adolescents (1980-2000): an analysis of 55 studies of the $20 \mathrm{~m}$ shuttle run in 11 countries. Sports Med 2003;33: 285-300.

44. Krahenbuhl GS, Skinner JS, Kohrt WM. Developmental aspects of maximal aerobic power in children. $E x$ - erc Sport Sci Rev 1985;13:503-38.

45. Rowland T, Goff D, Martel L, Ferrone L. Influence of cardiac functional capacity on gender differences in maximal oxygen uptake in children. Chest 2000;117:629-35.

46. Ekelund U, Poortvliet E, Nilsson A, Yngve A, Michael A, Sjöström M. Physical activity in relation to aerobic fitness and body fat in 14- to 15-year-old boys and girls. Eur J Appl Physiol 2001;85:195-201.

47. Sirard RJ, Russell RP. Physical activity assessment in children and adolescents. Sports Med 2001;31:439-54.

48. Hager RL, Tucker LA, Seljaas GT. Aerobic fitness, blood lipids, and body fat in children. Am J Public Health 1995;85:1702-6.

49. Janssen I, Katzmarzyk PT, Srinivasan SR, Chen W, Malina R, Bouchard C et al. Combined influence of body mass index and waist circumference on coronary artery disease risk factors among children and adolescents. Pediatrics 2005;115:1623-30.

50. Klasson-Heggebo L, Andersen LB, Wennlof AH, Sardinha L B, Harro M, Froberg K et al. Graded associations between cardiorespiratory fitness, fatness, and blood pressure in children and adolescents $\mathrm{Br} J$ Sports Med 2006;40:25-9.

51. Hussey J, Bell C, Bennett K, O’Dwyer J, Gormley J. Relationship between the intensity of physical activity, inactivity, cardiorespiratory fitness and body composition in 7-10-year-old Dublin children. Br J Sports Med 2007;41:311-6.

52. Grundy SM, Blackburn G, Higgins M, Lauer R, Perri MG, Ryan D. Physical activity in the prevention and treatment of obesity and its comorbidities. Med Sci Sports Exerc 1999;31:502-8.

53. Chen W, Lin CC, Peng CT, Li CI, Wu HC, Chiang J et al. Approaching healthy body mass index norms for children and adolescents from health-related physical fitness. Obes Rev 2002;3:225-32.

54. Riddoch C, Savage JM, Murphy N, Cran GW, Boreham C. Long term health implications of fitness and physical activity patterns. Arch Dis Child 1991;66:1426-33.

55. McKenzie TL, Li D, Derby C, Webber LS, Luepker RV, Cribb P. Maintenance of effects of the CATCH physical education program: results from the CATCH-ON study. Health Educ Behav 2003;30:447-62.

56. McKenzie TL, Sallis JF, Kolody B, Faucette F. Long term effects of a physical education curriculum and staff development program: SPARK. Res Q Exerc Sport 1997;68:280-91. 